\title{
COMPARATIVE ANALYSIS OF A PASSIVE SYSTEM WITH AN ACTIVE WATER HEATING SYSTEM BY MEANS OF VACUUM SOLAR COLLECTOR GLASS TUBES
}

\author{
J. D. Naranjo, \\ C. A. Ancines, \\ C. F. Dos Santos, \\ and A. Krenzinger \\ ${ }^{a}$ Universidade Federal do Rio Grande do Sul \\ Departamento de Engenharia Mecânica \\ Laboratório de Energia Solar \\ Av. Bento Gonçalves, 9500 Prédio 42712 \\ Porto Alegre, Rio Grande do Sul, Brasi
}

Received: April 10, 2016

Revised: May 15, 2016

Accepted: June 13, 2016

\section{ABSTRACT}

The importance of renewable energy conversion in heat generation systems is increasing. Being a form of clean energy production, solar water heating systems can substitute part of the electricity consumption in Brazilian energy matrix. Beyond the environmental benefits, the use of such systems brings economic benefits to the country and especially those who use them, saving the use of other energy sources for water heating. In Brazil, the solar water heating is carried out mainly by flat solar collectors, a widely known technology produced in the country at low prices. Nowadays another technology is being used: the evacuated solar collectors. These collectors are being worldwide produced on a large scale and they are imported and inserted at competitive prices in the domestic market. Therefore, it is necessary to understand these systems and their operation to avoid errors in their installation and optimize their use. This work accomplishes a comparative analysis of a solar water heating system composed by a waterin-glass evacuated tube solar collector working in forced circulation, varying the flow, with the same system working in thermosyphon circulation. This comparison was performed by determining the annual energy the system can produce for each type of circulation, which was calculated based on the ISO 9459-2 standard and the climatic data of Porto Alegre city, Rio Grande Do Sul State. To perform these measures, a testing bench was mounted with sensors and measuring instruments which were calibrated before use. The results show that the system with thermosyphon circulation produces more annual energy than the forced circulation system where the water temperature stratification in the thermal reservoir was lower.

Keywords: solar collector, vacuum tube, thermosyphon circulation, forced circulation

\section{NOMENCLATURE}

reservoir outlet temperature to the collector, ${ }^{\circ} \mathrm{C}$

T2 collector inlet temperature, ${ }^{\circ} \mathrm{C}$

T3 collector output temperature, ${ }^{\circ} \mathrm{C}$

$\mathrm{T} 4$ inlet temperature in the collector tank, ${ }^{\circ} \mathrm{C}$

T5 consumption temperature, ${ }^{\circ} \mathrm{C}$

T6 cold water temperature, ${ }^{\circ} \mathrm{C}$

T7 temperature inside the water tank, ${ }^{\circ} \mathrm{C}$

T8 ambient temperature, ${ }^{\circ} \mathrm{C}$

T9 temperature inside layer 1 the container, ${ }^{\circ} \mathrm{C}$

T10 temperature layer 2 inside the reservoir, ${ }^{\circ} \mathrm{C}$

T11 temperature layer 3 inside the shell, ${ }^{\circ} \mathrm{C}$

T12 temperature layer 4 inside the shell, ${ }^{\circ} \mathrm{C}$

S1 meter flow between the collector and the reservoir, L/min

S2 meter flow water consumption, $\mathrm{L} / \mathrm{min}$

$\mathrm{R} 1$ radiation sensor, $\mathrm{W} / \mathrm{m}^{2}$

\section{INTRODUCTION}

In recent decades, solar power is gaining importance as a viable alternative. Before demand associated with the decrease in non-renewable energy sources reserves, as well as growing concern to use sources of energy more friendly to the environment. According to the Brazilian Association of Refrigeration, Air Conditioning and Heating (ABRAVA), the solar water heating system is a clean form of energy production, can be inserted as an equivalent already part of the electrical energy matrix of Brazil, as shown in Figure 1, where equivalence for comparison in electrical power to the amount of solar heating produced in Brazil is shown. The use of such systems demands an initial cost, but can be compensated with the economic and environmental benefits that brings with it because they avoid the use of other forms of energy, increasing net income to decrease spending on heating water, in addition to reducing the use of polluting forms of energy that emit greenhouse gases (GHG), helping to preserve the environment.

It should be noted that most of the solar water heating in Brazil is installed with solar flat plate collectors, as this technology is already well known and manufactured in the country, at a relatively low cost. There are other technologies for solar water 
heating, as evacuated tubes collectors. These have been studied for decades, but the high cost of manufacturing in the past, limited its use to applications where they were really essential, such as industrial heating at medium temperature (between $80^{\circ} \mathrm{C}$ and $150^{\circ} \mathrm{C}$ ). The main characteristics of evacuated tubular collectors are its selective surface and the insulation performed by the vacuum. Use of this type of collector is suitable in countries with severe winters, where heat loss virtually unfeasible the use of conventional solar collectors.

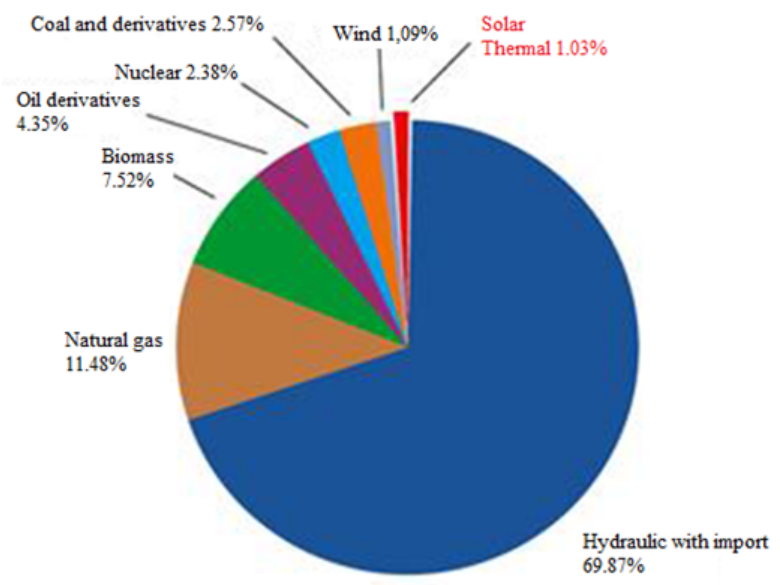

Figure 1. Brazilian electrical energy matrix in 2013, including solar thermal energy. Fonte: Energia Solar Térmica - ABRAVA (2014).

This work presents the results of the comparison of a water heating system through a solar collector glass vacuum tubes, heat extraction by direct transfer, when operating in forced circulation with the same system operating by thermosiphon (natural circulation). This comparison is performed by determining the annual energy that produce suck systems for each type of water circulation, which is calculated using as reference the ISO 9459-2 standard.

\section{METHODOLOGY}

The experimental setup was carried out in accordance with Figure 2 below. The tank is $250 \mathrm{~L}$ and the piping system is PPR tubes (polypropylene) of $32 \mathrm{~mm}$ diameter. Temperature sensors, flow meters and a pumping system were installed for the tests.

The indicated components in Figure 2 are: 1cold water box; 2- horizontal reservoir; 3- evacuated glass tubes solar collector; 4- circulation pump; 5- air vent; 6- connection pipes. And sensors: T1- reservoir outlet temperature to the collector; T2- collector inlet temperature; T3- collector output temperature; T4inlet temperature in the collector tank; T5consumption temperature; T6- cold water temperature; T7- temperature inside the water tank;
T8- Ambient temperature; T9- temperature inside layer 1 the container; T10 Temperature layer 2 inside the reservoir; T11- temperature layer 3 inside the shell; T12- temperature layer 4 inside the shell; S1meter flow between the collector and the reservoir; S2 meter flow water consumption; R1- radiation sensor (pyranometer and pirheliometer, with piranometer positioned in the collector plane).

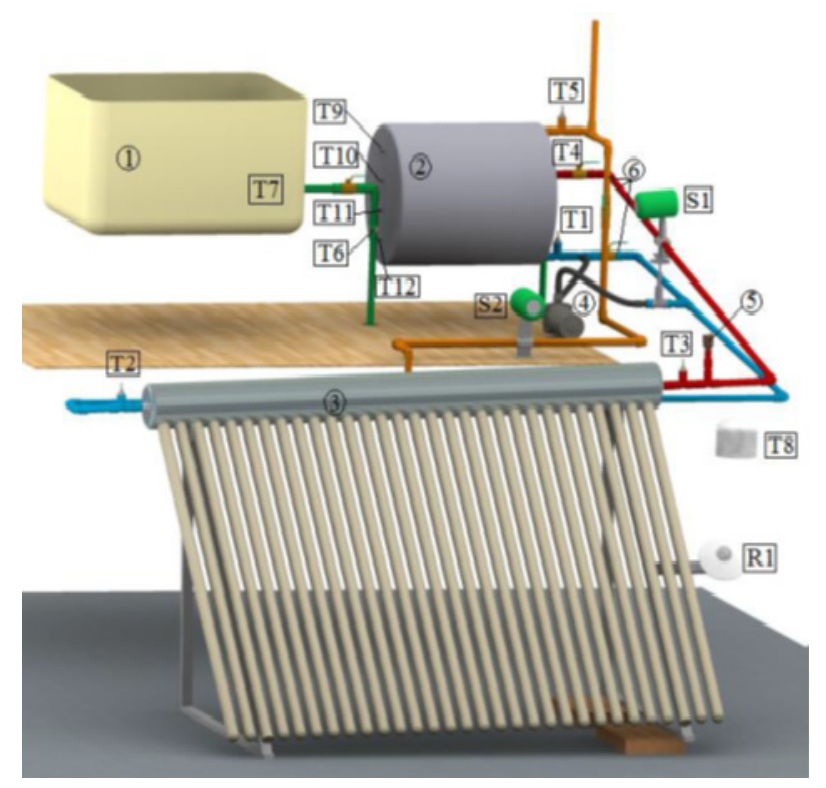

Figure 2. Components and sensors water heating system by means of a solar collector evacuated glass tubes.

With this system fitted, a comparison was performed between the active and passive water heating systems using as parameter the energy that each can produce every day throughout the year. To determine the production of each system ISO 9459-2 standard was used as reference this standard establishes the procedures to calculate the energy produced by water heating systems using solar radiation without auxiliary power assistance, allowing determine the daily performance system, the loss factor and the degree of stratification in the reservoir to thereby calculate the annual yield from known climatic conditions and the volume of a single hot water extraction performed at the end of each day.

In the process of comparison of heating systems measurements of volumetric flow by thermosiphon were carried out between the collector and the reservoir tank, in order to study their behavior in different conditions of irradiance and collector inlet temperature.

The method for determining the energy produced by the water heating system, according to the ISO 9459-2 standard, consists of a number of outdoor system tests, one day duration (minimum six day test), and a test to determine the degree of stratification of the reservoir tank and a night test to determine its thermal loss. Every day assays are 
independent of one another, where a single drain the end of each day while maintaining constant the inlet water temperature in the system and the volumetric flow rate of water drainage is performed. It is understood as the day of the test period 6 hours before and 6 hours after solar noon. From the above testing and knowing the irradiance place at room temperature, the temperature of the cold water and hot water daily consumption of the standard describes procedures for calculating the energy that the system can produce throughout the year; the calculation takes into account the thermal losses of the tank overnight and the energy remaining in the reservoir even when all the hot water is consumed the previous day.

The variation from the norm and the procedure adopted in this paper is not to carry out drainage at the end of each day of testing and calculating the daily performance using the system as a calorimeter. Morrison et al. (2004) used a similar procedure to determine the performance of a solar collector coupled evacuated tubes, using the ISO 9459-2 standard, but without performing the drainage at the end of the day and using the collector tank as a calorimeter to determine the daily gain energy. In calculating the energy the author has included all the water mass contained in the collector, in which case the collector coupled with tank corresponds to the mass in the tank and evacuated tubes.

To use the water heating system such as a calorimeter, this was divided into three different parts: thermal tank, solar collector evacuated tubes and connecting pipes.

The reservoir shown in Figure 2, was divided into four layers with temperature sensors arranged in each half as is displayed on the left of Figure 3. The temperature sensor $\mathrm{T} 9$ corresponds to the layer 1 , the sensor T10, layer 2 , the T11 sensor to layer 3 and layer 4 sensor to T12, where the volume of water contained in the layer 1 is $61.9 \mathrm{~L}$, layer $266.2 \mathrm{~L}$, on layer $366 \mathrm{~L}$, and layer $459.7 \mathrm{~L}$.

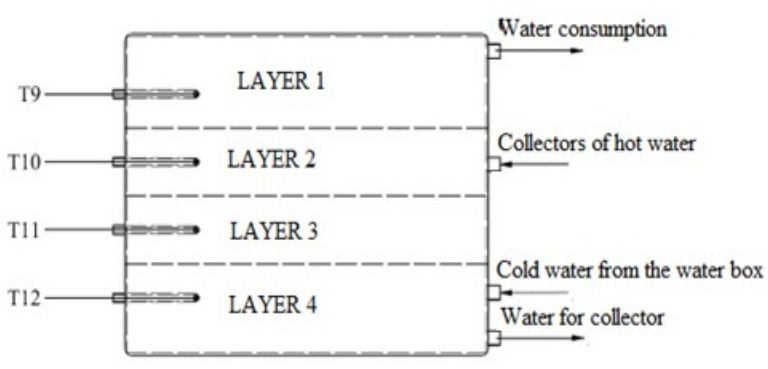

Figure 3. Layers of hot water tank reservoir.

\section{RESULTS}

By using the ISO 9459-2 standard, by results were obtained comparing water heating system with thermosyphon circulation for and forced circulation.
Figure 4 shows the monthly energy production of these two systems.

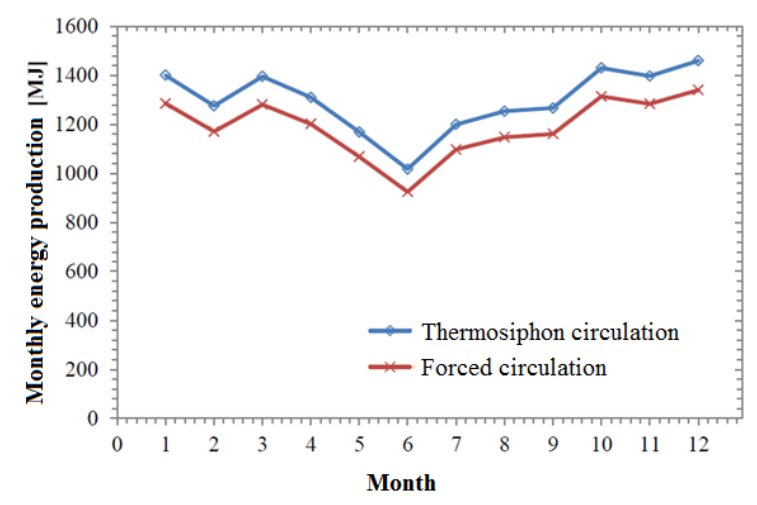

Figure 4. Monthly energy production water heating system through solar collector evacuated tubes working in circulation by thermosyphon and forced circulation.

Table 1 shows the values of the monthly energy production for each kind of water circulation and likewise the annual value are shown. As is visualized in Figure 4 and Table 1, the of values energy produced by the water heating system working in thermosyphon circulation are above the values for forced circulation system, having a difference in annual production of approximately $1300 \mathrm{MJ}$, or a relative difference of $8.3 \%$.

Table 1. Production of energy water heating system.

\begin{tabular}{|c|c|c|}
\hline \multicolumn{3}{|c|}{ Monthly energy production (MJ) } \\
\hline Month & $\begin{array}{c}\text { Circulation in } \\
\text { thermosiphon }\end{array}$ & $\begin{array}{c}\text { Forced } \\
\text { Circularion }\end{array}$ \\
\hline 1 & 1400.76 & 1285.47 \\
\hline 2 & 1275.48 & 1170.91 \\
\hline 3 & 1395.63 & 1280.88 \\
\hline 4 & 1310.10 & 1202.06 \\
\hline 5 & 1168.75 & 1068.41 \\
\hline 6 & 1017.37 & 925.29 \\
\hline 7 & 1200.08 & 1097.36 \\
\hline 8 & 1253.96 & 1147.54 \\
\hline 9 & 1266.84 & 1161.17 \\
\hline 10 & 1430.36 & 1313.99 \\
\hline 11 & 1397.28 & 1284.08 \\
\hline 12 & 1459.79 & 1340.54 \\
\hline \multirow{2}{*}{$\begin{array}{c}\text { Energy produced } \\
\text { in the year (MJ) }\end{array}$} & 15576.40 & 14277.71 \\
\hline
\end{tabular}

The tests were performed in forced circulation using the flow rate stated in the Brazilian standard NBR 15747-2, which corresponds to $0.02 \mathrm{~kg} / \mathrm{s}$ per $\mathrm{m} 2$ gross solar collector area. For the solar collector gross area tested, $2.8 \mathrm{~m} 2$, this represents a $0.056 \mathrm{~kg} / \mathrm{s}$ mass flow rate, for that is, a volumetric flow rate of $3.4 \mathrm{~L} / \mathrm{min}$.

To better observe the behavior of the system in each circulation type, we compared two test days, where one test day corresponds to system working in 
forced circulation and the other in thermosyphon circulation, Figures 5 and 6 were prepared. With the data obtained in these two days. Figure 5 compares the temperature of the evacuated tubes solar collector head when working with forced circulation and with thermosiphon circulation. The inlet temperature corresponding to the temperature sensor $\mathrm{T} 2$ and the outlet temperature corresponds to the temperature sensor T3. It is also possible note that the temperature at the outlet with in thermosiphon circulation system head (T3) has a parabolic behavior that achieves a maximum temperature of about $80^{\circ} \mathrm{C}$ around noon, while the temperature at the entrance $\mathrm{T} 2$ remains almost constant during the day. Before 9 am increments until the flow-through thermosiphon be sufficient to remove heat from the collector head and is maintained nearly constant the late afternoon when the irradiance falls and the flow decreases, increasing again. The inlet temperature increases because the flow speed is almost zero, making the heat diffusion more important than the advection. Heat exchange occurs between the hot water flowing out of tubes and is discharged into the head, and the water is inside the same inlet pipe. In the system with forced circulation, the inlet and outlet head, temperature T2 and T3 sensor respectively, have behavior similar to a straight line with positive slope where the inlet temperature increases with increasing temperature at the outlet, making the difference between the two is not larger than $6^{\circ} \mathrm{C}$ along the day; In this case the outlet temperature of the collector head reaches maximum values of $56^{\circ} \mathrm{C}$ near the end of the afternoon.

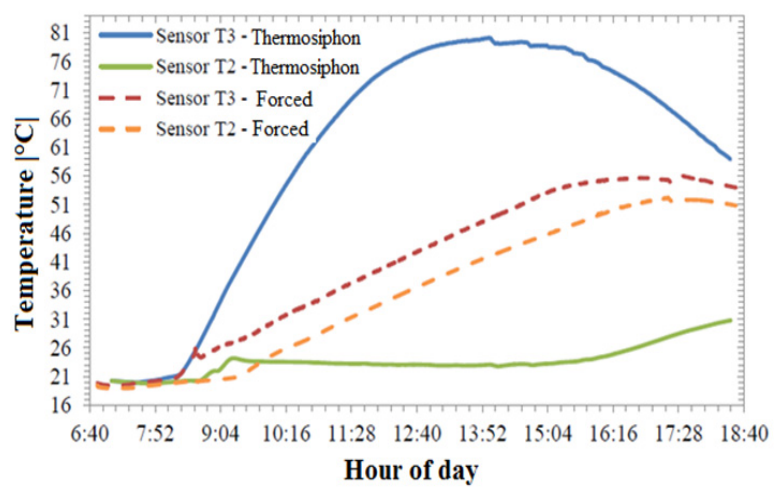

Figure 5. Inlet temperature $\mathrm{T} 2$ and outlet temperature $\mathrm{T} 3$ of solar collector head for thermosyphon and forced circulation.

In Figure 6, the temperatures of the water inside the tank layers are compared. The heating system configured to operate both as thermosiphon and forced circulation. The temperature of the layer 1 corresponds to temperature sensor $\mathrm{T} 9$, the temperature of the layer 2 to the temperature sensor $\mathrm{T} 10$, the temperature $\mathrm{T} 11$ of the layer 3 to the temperature sensor and the temperature of layer 4 the temperature sensor T12, as shown in Figure 3.

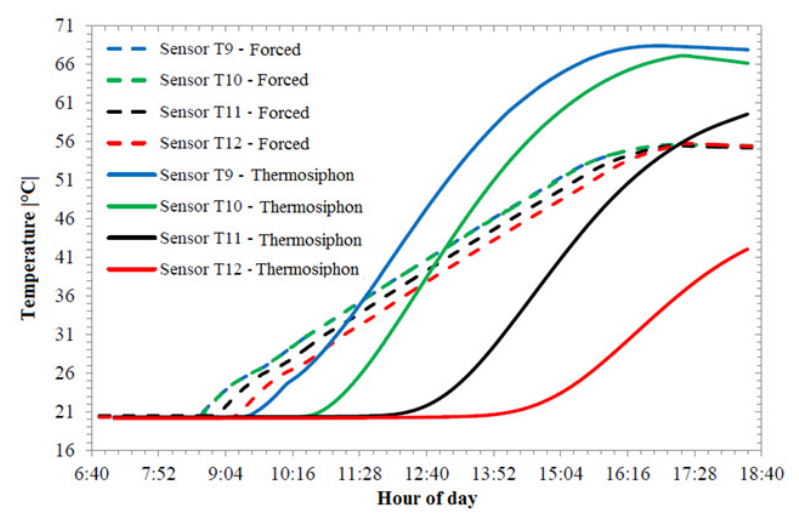

Figure 6. Temperature of the layers in the heating system reservoir operating with thermosiphon circulation and forced circulation.

From Figure 6 it can be seen that when the system works in thermosyphon circulation, the temperature inside the container is more stratified, besides higher than temperatures observed with the system in forced circulation.

Although the system configured to operate with forced circulation reaches a more uniform temperature of the water inside the tank and this temperature is equal to the maximum temperature reached by the collector, the energy produced at the end of the day is lesser than that obtained by the system working with thermosiphon circulation. A lower yield in the reservoir tank final temperature can be seen, where most of the water volume is at a lower temperature than the water temperature reached by natural circulation system.

In the previous work carried out by Harding and Zhiqiang (1985), where the solar collector heat extraction evacuated by direct transfer tubes operating in thermosyphon was studied, it was observed that the thermosyphon flow depends on the distance between the head of the pipes and reservoir tank; it was also observed that the higher the inlet temperature in the head, the greater the flow. The same work was the subject of a first approximation, which, for this type of collector, the buoyancy effect inside the evacuated tubes, responsible for the transfer of heat to the head, do not contribute to the flow in thermo between the head and the tank reservoir; but the efficiency of these buoyant effect on heat transfer depends on the collector slope.

Shah and Furbo (2007) studied the solar collector behavior of evacuated tubes with heat extraction by direct transfer, through numerical simulations. The solar collector configuration studied by them consisted of a vertical head with horizontal tubes, which was analyzed for different input flows in the head and different tube lengths and reached the conclusion that the flow inside the exhaust pipe is not affected by the flow head. The optimum flow rates in the head entry determined by them are between 0.4 $\mathrm{kg} / \mathrm{min}$ to $1 \mathrm{~kg} / \mathrm{min}$ or between $0.0067 \mathrm{~kg} / \mathrm{s}$ and 0.016 
$\mathrm{kg} / \mathrm{s}$. These flow rates are lower than suggested by the Brazilian standard NBR 15742-2 (2009) and used in this work $(0.056 \mathrm{~kg} / \mathrm{s})$.

\section{CONCLUSIONS}

For this paper a test bench using the existing water heating system was assembled in LABSOL Laboratory - UFRGS, allowing the heating system test through evacuated tubes operating in circulation for thermosyphon and forced circulation.

After assembly and measurements, the water heating system comparison was made through a heat extraction by direct transfer vacuum solar collector glass tube operating with forced circulation and also with the same system operating in thermosyphon circulation, where the results show that the system configured for natural circulation (thermosiphon) has a better performance than the system configured for forced circulation, showing higher annual energy production that was determined using as reference the standard ISO 9459-2 and climatic data of Porto Alegre city, Rio Grande do Sul state.

Among the results, it was observed that the heating system operating in thermosyphon circulation reaches a higher temperature stratification in the water inside the tank, which favors a greater system efficiency, and achieves higher temperatures within the reservoir, compared with the system operating in forced circulation.

\section{REFERENCES}

ABNT, Associação Brasileira de Normas Técnicas, NBR 15747-2, 2009, Sistemas Solares Térmicos e Seus Componentes - Coletores Solares Parte 2: Métodos de Ensaio, Brazil. (in Portuguese)

ABRAVA, Associação Brasileira de Refrigeração, Ar Condicionado, Ventilação e Aquecimento, 2014, Energia Solar Térmica, Participação na Matriz Energética e Contribuições Socioeconômicas ao Brasil, Brazil. (in Portuguese)

Harding, G. L., and Zhiqiang, Y., 1985, Thermosiphon Circulation in Solar Water Heaters Incorporating Evacuated Tubular Collectors and a Novel Water-in-glass Manifold, Solar Energy, Vol. 34, pp. 13-18.

ISO, International Organization for Standardization, ISO 9459-2, 1995, Solar Heating Domestic Water Heating Systems - Part 2: Outdoor Test Methods for System Performance Characterization and Yearly Performance Prediction of Solar-only Systems, Genève, Switzerland.

Morrison, G. L., Budihardjo, I., and Behnia, M., 2004, Water-in-Glass Evacuated Tube Solar Water Heaters, Solar Energy, Vol. 76, pp. 135-140.

Shah, L. J., and Furbo, S., 2007, Theoretical Flow Investigation of an all Glass Evacuated Tubular Collector, Solar Energy, Vol. 81, pp. 822-828. 